\title{
Structure-activity relationship of three synthesized benzimidazole-based oligosaccharides in human platelet activation
}

\author{
YI CHANG $^{1-3^{*}}$, WEN-HSIEN HSU ${ }^{2,4^{*}}$, WEN-BIN YANG ${ }^{5}$, THANASEKARAN JAYAKUMAR ${ }^{3}$, \\ TZU-YIN LEE ${ }^{3}$, JOEN-RONG SHEU ${ }^{3}$, WAN-JUNG LU ${ }^{3,6}$ and JIUN-YI LI ${ }^{3,7}$ \\ ${ }^{1}$ Department of Anesthesiology, Shin Kong Wu Ho-Su Memorial Hospital, Taipei 111; ${ }^{2}$ School of Medicine, \\ Fu-Jen Catholic University, Xin Zhuang, New Taipei City 242; ${ }^{3}$ Department of Pharmacology and \\ Graduate Institute of Medical Sciences, College of Medicine, Taipei Medical University, Taipei 110; \\ ${ }^{4}$ Department of Surgery, Wan-Fang Hospital, Taipei Medical University, Taipei 116; ${ }^{5}$ Genomics Research Center, \\ Academia Sinica, Taipei 115; ${ }^{6}$ Department of Medical Research and Translational Laboratory, Research Department, \\ Taipei Medical University Hospital, Taipei $110 ;{ }^{7}$ Department of Cardiovascular Surgery, \\ Mackay Memorial Hospital, and Mackay Medical College, Taipei 104, Taiwan, R.O.C.
}

Received January 14, 2016; Accepted September 5, 2017

DOI: $10.3892 / \mathrm{ijmm} .2017 .3133$

\begin{abstract}
Antiplatelet agents have considerable benefits in the treatment of thromboembolic diseases; however, these agents still have substantial limitations due to their severe side-effects. In this study, the antiplatelet activity of three newly synthesized saccharide based benzimidazole derivatives, M3BIM, Malto-BIM and Melibio-BIM, in collagen and thrombin-stimulated human platelets in vitro was examined. Among the compounds tested, only compound M3BIM exerted concentration $(20-60 \mu \mathrm{M})$-dependent inhibitory effects against collagen $(1 \mu \mathrm{g} / \mathrm{ml})$ and thrombin $(0.01 \mathrm{U} / \mathrm{ml})$-induced washed human platelet aggregation. Moreover, at a concentration of $60 \mu \mathrm{M}$, M3BIM distinctly abolished collagen-induced adenosine triphosphate (ATP) release and intracellular $\mathrm{Ca}^{2+}$ mobilization. Additionally, this compound attenuated the collagen-induced phosphorylation of $\mathrm{p} 47$, a marker of the activation of protein kinase $\mathrm{C}$ (PKC) and p38 mitogen-activated protein kinase (MAPK). However, Malto-BIM and Melibio-BIM were not effective in this regard. Moreover, the toxic effects of these compounds were evaluated using zebrafish embryo
\end{abstract}

Correspondence to: Dr Wan-Jung Lu, Department of Medical Research and Translational Laboratory, Research Department, Taipei Medical University Hospital, 252 Wu Hsing Street, Taipei 110, Taiwan, R.O.C.

E-mail: 144106@h.tmu.edu.tw

Dr Jiun-Yi Li, Department of Cardiovascular Surgery, Mackay Memorial Hospital and Mackay Medical College, Section 2, 92 Chung-Shan N. Road, Taipei 104, Taiwan, R.O.C.

E-mail: jyl5891@gmail.com

*Contributed equally

Key words: antiaggregant effect, benzimidazole, p38 mitogenactivated protein kinase/p47, adenosine triphosphate, $\mathrm{Ca}^{2+}$, zebrafish toxicity (ZET) assay, and the results revealed that all three compounds had no comparative cytotoxicity within the range of 25-200 $\mu \mathrm{M}$. Overall, the results of this study provide evidence for the inhibitory effects of M3BIM on collagen-induced platelet aggregation in vitro compared to other imidazole derivatives. The presence of 1-imidazolyl moiety at one end with a longer chain length (three sugar moieties) may be mainly responsible for the observed effects of M3BIM. These results suggest that compound M3BIM may be used as a potential candidate for the treatment of aberrant platelet activation-related diseases as it inhibits the activation of p47 and p38 MAPK, and reduces ATP release and $\mathrm{Ca}^{2+}$ mobilization.

\section{Introduction}

In developed countries, thromboembolic diseases are a leading cause of mortality and disability (1). Blood platelet activation and the plasma coagulation system play a crucial role in thrombus formation. Despite the fact that established antiplatelet agents, such as aspirin, clopidogrel and tirofiban, and anticoagulant agents, such as heparin and warfarin have been reported to be beneficial in the treatment of thromboembolic disease, they all have considerable limitations (2). Therefore, there is an urgent need from the clinical aspect for the development of more effective and safer antithrombotic agents. Although aspirin is the most economic and effective antiplatelet drug prescribed for the treatment of cardiovascular and cerebrovascular diseases, it nevertheless has untoward drawbacks, such as gastrointestinal bleeding and hemorrhagic stroke in patients with low cardiovascular risk (2).

Currently, the use of anticoagulants, such as warfarin and heparin is restricted due to their modest therapeutic benefits, limited clinical applications, and increased risk of bleeding and drug-induced thrombophilia. A number of available antiplatelet and anticoagulant agents have limited use in antithrombotic therapy (3). However, in recent years considerable progress has been made in the synthesis of oligosaccharides with the antico- 
agulant properties of heparin $(4,5)$. Unfortunately, the chemical synthesis of oligosaccharides remains a major challenge. As such, the development of efficient strategies for oligosaccharide synthesis stands out as a demanding area of research.

Various substituted derivatives of benzimidazole exhibit marked biological activity, such as antitumor/antiproliferative/ anticancer activity, antimicrobial activity (including anti-HIV activity), antioxidant and cysticidal activities. Compounds with the chemical structure of a benzimidazole backbone have shown antiplatelet activities (6) or anticoagulant activities through their inhibitory effects on coagulation factors (7). The antiplatelet (anti-aggregation and anti-coagulation) effects of RU-891, a compound of 9-[2-(3,4-dioxyphenyl)-2-oxoethyl]2,3-dihydro imidazo[1,2-a]benzimidazole hydrobromide has been reported both in vitro and in vivo (8). It has been reported that the ability of heparin and related compounds that induce thrombocytopenia is closely associated with the structure of the polysaccharides, and particularly to its negative charge and to the length of the molecules (9). Therefore, this study was designed to investigate the effects of the newly synthesized benzimidazole-based saccharides, M3BIM, Malto-BIM and Melibio-BIM, on platelet activation. The molecular basis of their effects was also confirmed by assessing the roles of adenosine triphosphate (ATP) release, $\mathrm{Ca}^{2+}$ mobilization, p38 mitogen-activated protein kinase (MAPK), and p47 in the collagen-mediated responses in platelets.

\section{Materials and methods}

Materials. Collagen (type I), thrombin, luciferin-luciferase, maltotriose, maltose and melibiose were all purchased from Sigma (St. Louis, MO, USA). Fura 2-AM and fluorescein isothiocyanate (FITC) were from Molecular Probe (Eugene, OR, USA); anti-phospho-(Ser) PKC substrate (cat. no. 2261), anti-phospho-p38 MAPK (Ser $\left.{ }^{180} / \mathrm{Tyr}^{182}\right)$ polyclonal antibody (pAb) (cat. no. 9211) and anti-p38 MAPK (5F11) monoclonal antibody (mAb) (cat. no. 9217) were from Cell Signaling Technology (Beverly, MA, USA); the pleckstrin pAb (cat. no. GTX17020) was from GeneTex (Irvine, CA, USA). Ortho-phenyl diamine (cat. no. 523121), iodine (cat. no. 104761), ethyl acetate (cat. no. 100789) and acetic acid (cat. no. 100063) were purchased from Merck Millipore (Billerica, MA, USA). Hybond-P polyvinylidene difluoride membrane, enhanced chemiluminescence (ECL), western blot detection reagent and analysis system, horseradish peroxidase (HRP)-conjugated donkey anti-rabbit immunoglobulin G ( $\operatorname{IgG}$ ) (cat. no. NA934), and sheep anti-mouse IgG (cat. no. NA931) were from Amersham (Buckinghamshire, UK).

Synthesis and purification of M3BIM, Malto-BIM and Melibio-BIM. According to the method previously described by Lin et al (10), the compound M3BIM was synthesized and purified by the oxidative condensation of maltotriose. Briefly, a mixture of D-maltotriose monohydrate $(50.4 \mathrm{mg}, 0.1 \mathrm{mM})$ and $o$-phenylenediamine $(21.6 \mathrm{mg}, 0.2 \mathrm{mM})$ was stirred with iodine $(25 \mathrm{mg}, 0.1 \mathrm{mM})$ in $3 \mathrm{ml}$ of $\mathrm{AcOH}$ for $30 \mathrm{~h}$ at room temperature. The reaction was completed in $6 \mathrm{~h}$ as indicated by the following thin layer chromatography (TLC) analysis: (acetone/ethyl acetate/water/acetic acid, 60:30:20:1) $R f$ 0.44; [R] $25 \mathrm{D}+55.40\left(c\right.$ 1.0, $\left.\mathrm{H}_{2} \mathrm{O}\right)$. The reaction mixture was triturated with ethyl acetate to yield precipitates, which were collected by filtration using a nylon membrane filter. The aldonaphthimidazole products prepared as such were practically pure for characterization. The crude product was purified by C18 reversed-phase silica gel column chromatography (methanol/water, 1-30\% as gradient) to yield M3BIM (30 mg, 51\% yield, $\mathrm{C}_{24} \mathrm{H}_{36} \mathrm{~N}_{2} \mathrm{O}_{15}$, yellowish foam).

The compounds Malto-BIM and Melibio-BIM were prepared and purified by the oxidative condensation of respective maltose and melibiose (10). To this, a mixture of each maltose and melibiose $(34.2 \mathrm{mg}, 0.1 \mathrm{mM})$ and $o$-phenylenediamine (21.6 mg, $0.2 \mathrm{mM}$ ) was stirred with iodine $(25 \mathrm{mg}, 0.1 \mathrm{mM})$ in $3 \mathrm{ml}$ of $\mathrm{AcOH}$ for $24 \mathrm{~h}$ at room temperature. The reaction was completed in $12 \mathrm{~h}$. The reaction mixture was triturated with EtOAc to yiled precipitates, which were collected by filtration using a nylon membrane filter. The crude product was purified by $\mathrm{C} 18$ reversed-phase silica gel column chromatography ( $\mathrm{MeOH} / \mathrm{H}_{2} \mathrm{O}, 1-30 \%$ as gradient) to afford the desired product of Malto-BIM (44.2 mg, 92\% yield, $\mathrm{C}_{18} \mathrm{H}_{26} \mathrm{~N}_{2} \mathrm{O}_{10}$; brownish solid) and Melibio-BIM (38.4 mg, 80\% yield, $\mathrm{C}_{18} \mathrm{H}_{26} \mathrm{~N}_{2} \mathrm{O}_{10}$; brownish solid). All compounds were dissolved in DMSO and stored at $4^{\circ} \mathrm{C}$.

Platelet preparation. Blood was collected from healthy human volunteers (following informed consent) who did not take medication during the preceding 2 weeks and was mixed with acid-citrate-dextrose solution (1:9). Human platelet suspensions were prepared following the methods described by Sheu et al (11). Briefly, the blood samples were subjected to centrifugation at $120 \mathrm{x} \mathrm{g}$ for $10 \mathrm{~min}$, and platelet-rich plasma (PRP) was collected. PRP was supplemented with prostaglandin $\mathrm{E}_{1}\left(\mathrm{PGE}_{1} ; 0.5 \mu \mathrm{M}\right)$ and heparin $(6.4 \mathrm{IU} / \mathrm{ml})$ and then incubated for $10 \mathrm{~min}$ at $37^{\circ} \mathrm{C}$. Following centrifugation at $500 \mathrm{x} \mathrm{g}$ for $10 \mathrm{~min}$, the platelet pellets were suspended in Tyrode's solution containing $3.5 \mathrm{mg} / \mathrm{ml}$ bovine serum albumin (BSA), pH 7.3 ( $\mathrm{NaCl} 11.9 \mathrm{mM}, \mathrm{KCl} 2.7 \mathrm{mM}, \mathrm{MgCl}_{2}$ $2.1 \mathrm{mM}, \mathrm{NaH}_{2} \mathrm{PO}_{4} 0.4 \mathrm{mM}, \mathrm{NaHCO}_{3} 11.9 \mathrm{mM}$ and glucose $11.1 \mathrm{mM})$. Subsequently, $\mathrm{PGE}_{1}(0.5 \mu \mathrm{M})$, apyrase $(1.0 \mathrm{U} / \mathrm{ml})$, and heparin $(6.4 \mathrm{IU} / \mathrm{ml})$ were added, and the mixture was incubated for $10 \mathrm{~min}$ at $37^{\circ} \mathrm{C}$. The mixtures were centrifuged at $500 \mathrm{x} \mathrm{g}$ for $10 \mathrm{~min}$ and subjected for the repeated washing procedure. Finally, the platelet pellets were resuspended in Tyrode's solution, and then calcium chloride was added to platelet suspensions in which the concentration of $\mathrm{Ca}^{2+}$ was $1 \mathrm{mM}$. This study was approved by the Institutional Review Board of Taipei Medical University and conformed to the directives of the Helsinki Declaration.

Platelet aggregation. Platelet aggregation was examined as previously described (11) and monitored by measuring light transmission via a Lumi-Aggregometer (Payton Associates, Scarborough, ON, Canada). Prior to the addition of agonists, such as collagen $(1 \mu \mathrm{g} / \mathrm{ml})$ to induce platelet aggregation, the platelet suspensions $\left(3.6 \times 10^{8}\right.$ cells $\left./ \mathrm{ml}\right)$ were pre-treated with various concentrations (20-60 $\mu \mathrm{M})$ of M3BIM, Malto-BIM and Melibio-BIM or an isovolumetric solvent control (0.5\% DMSO) for $3 \mathrm{~min}$. Moreover, the platelets were pre-treated with 40-80 $\mu \mathrm{M}$ of M3BIM, Malto-BIM and Melibio-BIM for thrombin $(0.01 \mathrm{U} / \mathrm{ml})$-induced aggregation. A light-transmission unit was used to present the extent of platelet aggregation. 
ATP release assay. The washed platelets were pre-incubated with $60 \mu \mathrm{M}$ of each M3BIM, Malto-BIM, and Melibio-BIM for $3 \mathrm{~min}$ at $37^{\circ} \mathrm{C}$ and then stimulated with collagen. The reaction was terminated, the samples were centrifuged and supernatants were used for the assay. For the measurement of ATP release, a $20 \mu 1$ of luciferin-luciferase mixture was added $1 \mathrm{~min}$ before adding the testing compounds or agonists, and the relative amount of ATP release was compared to the solvent control.

Measurement of relative $\mathrm{Ca}^{2+}$ mobilization. Citrated blood was centrifuged at $120 \mathrm{xg}$ for $10 \mathrm{~min}$. The supernatant (PRP) was incubated with $5 \mu \mathrm{M}$ Fura 2-AM for $1 \mathrm{~h}$. The platelets were then prepared as described above. Finally, the external $\mathrm{Ca}^{2+}$ concentration of the platelet suspensions was adjusted to $1 \mathrm{mM}$. The relative $\mathrm{Ca}^{2+}$ mobilization was measured as previously described (11).

Immunoblotting. The washed platelets $\left(1.2 \times 10^{9}\right.$ cells/ $\mathrm{ml})$ were pre-incubated with M3BIM, Malto-BIM and Melibio-BIM $(60 \mu \mathrm{M})$ or a solvent control for $3 \mathrm{~min}$, followed by the addition of $1 \mu \mathrm{g} / \mathrm{ml}$ collagen to trigger platelet activation. The platelets were immediately resuspended in lysis buffer. Samples containing protein $(80 \mu \mathrm{g})$ were separated by sodium dodecyl sulfate-polyacrylamide gel electrophoresis (SDS-PAGE) (12\%); proteins were electrotransferred using semidry transfer (Bio-Rad, Hercules, CA, USA). The blots were blocked with Tris-buffered saline with Tween-20 (TBST; $10 \mathrm{mM}$ Tris-base, $100 \mathrm{mM} \mathrm{NaCl}$, and $0.01 \%$ Tween-20) and then probed with p-p47 and p-p38 MAPK primary antibodies for $1 \mathrm{~h}$. The membranes were incubated with HRP-linked secondary antibodies for $1 \mathrm{~h}$ in TBST. Subsequently, the immunoreactive bands were detected by an ECL system. The bar graph depicts the ratios of semiquantitative results obtained by scanning reactive bands and quantifying the optical density using video densitometry (Bio-profil; Biolight Windows Application V2000.01; Vilber Lourmat, Marne la Vallée, France).

Zebrafish genotoxicity assay. The toxic effects of imidazolederived saccharides were tested in zebrafish-based assays. Zebrafish (Danio rerio) were obtained from the Zebrafish Core Facility of Taipei Medical University and maintained at $28^{\circ} \mathrm{C}$ on a $14 \mathrm{~h} \mathrm{light} / 10 \mathrm{~h}$ dark cycle. The embryos were incubated at $28^{\circ} \mathrm{C}$, and different developmental stages after fertilization (the zygote, cleavage, blastula, gastrula, segmentation, pharyngula, and hatching periods) were determined as previously described (12). Fifteen wild-type embryos each were treated with various concentrations of M3BIM, Malto-BIM and Melibio-BIM $(25,50$, 100 and $200 \mu \mathrm{M})$ or a solvent control (0.5\% DMSO) in a 24-well chamber. At 3 days post-fertilization (dpf), the percentage of embryos exhibiting developmental abnormalities and the survival rate were determined. The embryos were observed using an Olympus IX70-FL inverted fluorescence microscope (Olympus, Tokyo, Japan). Images were acquired using a SPOT digital camera system (Diagnostic Instruments, Sterling Heights, MI, USA) and assembled with ImageJ software.

Statistical analysis. The experimental results are expressed as the means \pm SEM and are accompanied by the number of observations. The experiments were assessed by the method of analysis of variance (ANOVA). If this analysis indicated signifi-

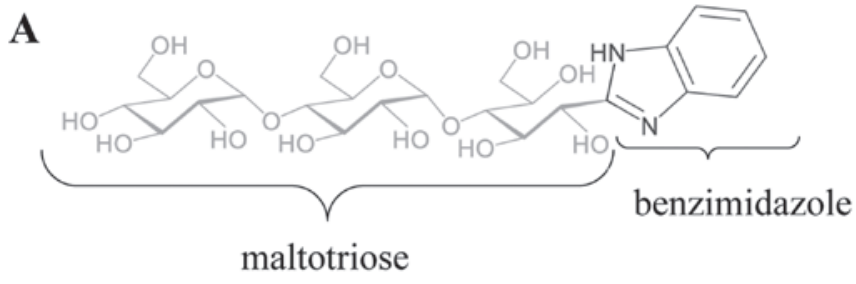

M3BIM

B

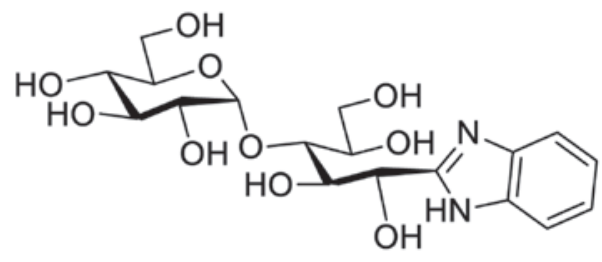

Malto-BIM

C

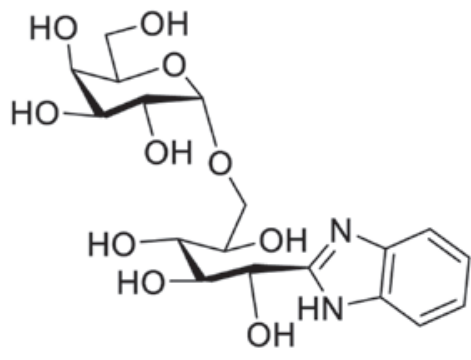

Melibio-BIM

Figure 1. Chemical structures of the newly synthesized imidazole-derived saccharide compounds (A) M3BIM, (B) Malto-BIM and (C) Melibio-BIM.

cant differences among the group means, then each group was compared using the Newman-Keuls method. A P-value of $<0.05$ was considered to indicate a statistically significant difference.

\section{Results}

Synthesis of benzimidazole derivatives. The novel benzimidazole derivatives of M3BIM [(1R,2R,3R)-1-(1H-benzo[d]imidazol-2yl)-3-(2R,3R,4R,5S,6R)-3,4-dihydroxy-6-(hydroxymethyl)-5-2R, $3 R, 4 S, 5 S, 6 R)-3,4,5$-trihydroxy-6-hydroxymethyl)tetrahydro- $2 \mathrm{H}-$ pyran-2-yl)oxy)tetrahydro-2H-pyran-2-yl)oxy) pentane-1,2,4,5tetraol], Malto-BIM $\left(1^{\prime} S, 2^{\prime} R, 3^{\prime} R, 4^{\prime} R-2\right)$-[1,2,4,5-tetrahydoxy-3- $O$ (2,3,4,5-tetrahydroxy- $\alpha$-D-glucopyranosyl)]pentyl- $1 H$-benzimidazole] and Melibio-BIM [(1'S,2'R,3'S,4'R)-2-[1,2,3,4-tetrahydoxy5-O-(2,3,4,5-tetrahydroxy- $\alpha$-D-glucopyranosyl)]pentyl- $1 H$-benzimidazole] were prepared by the oxidative condensation of maltotriose, maltose and melibiose, respectively as previously described by Lin et al (10). The chemical structures of the synthesized compounds M3BIM, Malto-BIM and Melibio-BIM are shown in Fig. 1.

M3BIM inhibits platelet aggregation induced by collagen and thrombin. We previously determined that collagen $(1 \mu \mathrm{g} / \mathrm{ml})$ 

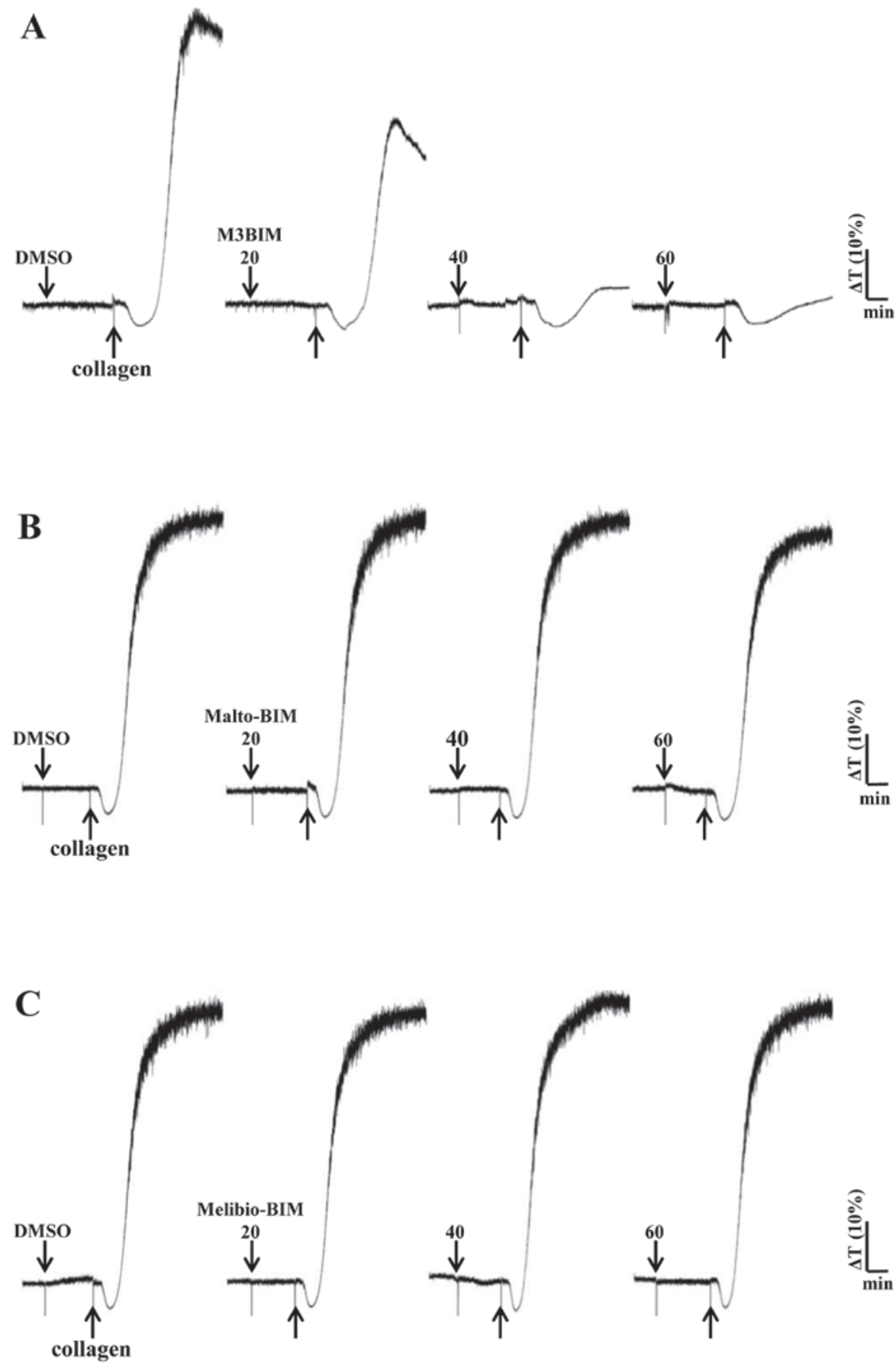

Figure 2. Effects of the test compounds on the inhibition of platelet aggregation in washed human platelets stimulated with collagen. Washed platelets (3.6x $10^{8}$ cells $/ \mathrm{ml}$ ) were pre-treated with 20-60 $\mu \mathrm{M}$ of each (A) M3BIM, (B) Malto-BIM and (C) Melibio-BIM, and then $1 \mu \mathrm{g} / \mathrm{ml}$ collagen was added to induce platelet aggregation. The profiles are representative examples of 4 similar experiments.

and thrombin $(0.01 \mathrm{U} / \mathrm{ml})$ induced complete platelet aggregation (28); hence, the present study employed these agonists to stimulate platelets and evaluate the effects of the test compounds on platelet aggregation. M3BIM potently inhibited collagen-induced platelet aggregation in a concentration-dependent manner (Fig. 2A). We also tested the compound M3BIM against thrombin $(0.01 \mathrm{U} / \mathrm{ml})$-induced platelet aggregation, and the results revealed that M3BIM $(40-80 \mu \mathrm{M})$ attenuated thrombin-induced platelet aggregation (Fig. 3A) and exhibiting similar pattern as collagen-induced aggregation (Fig. 2A). However, the compounds Malto-BIM and Melibio-BIM did not inhibit collagen (Fig. 2B and C) or thrombin-induced platelet aggregation (Fig. 3B and C). The observed inhibitory effects of M3BIM on agonist-induced platelet aggregation may be attributed to its chemical structure; namley the occurrence of a longer chain length (increased number of sugar moieties) than that of the other two compounds.

M3BIM suppresses collagen-induced ATP release and intracellular calcium levels. Since a previous study reported that granule secretions are critical markers of platelet activation prior to aggregation (13), the present study examined whether 

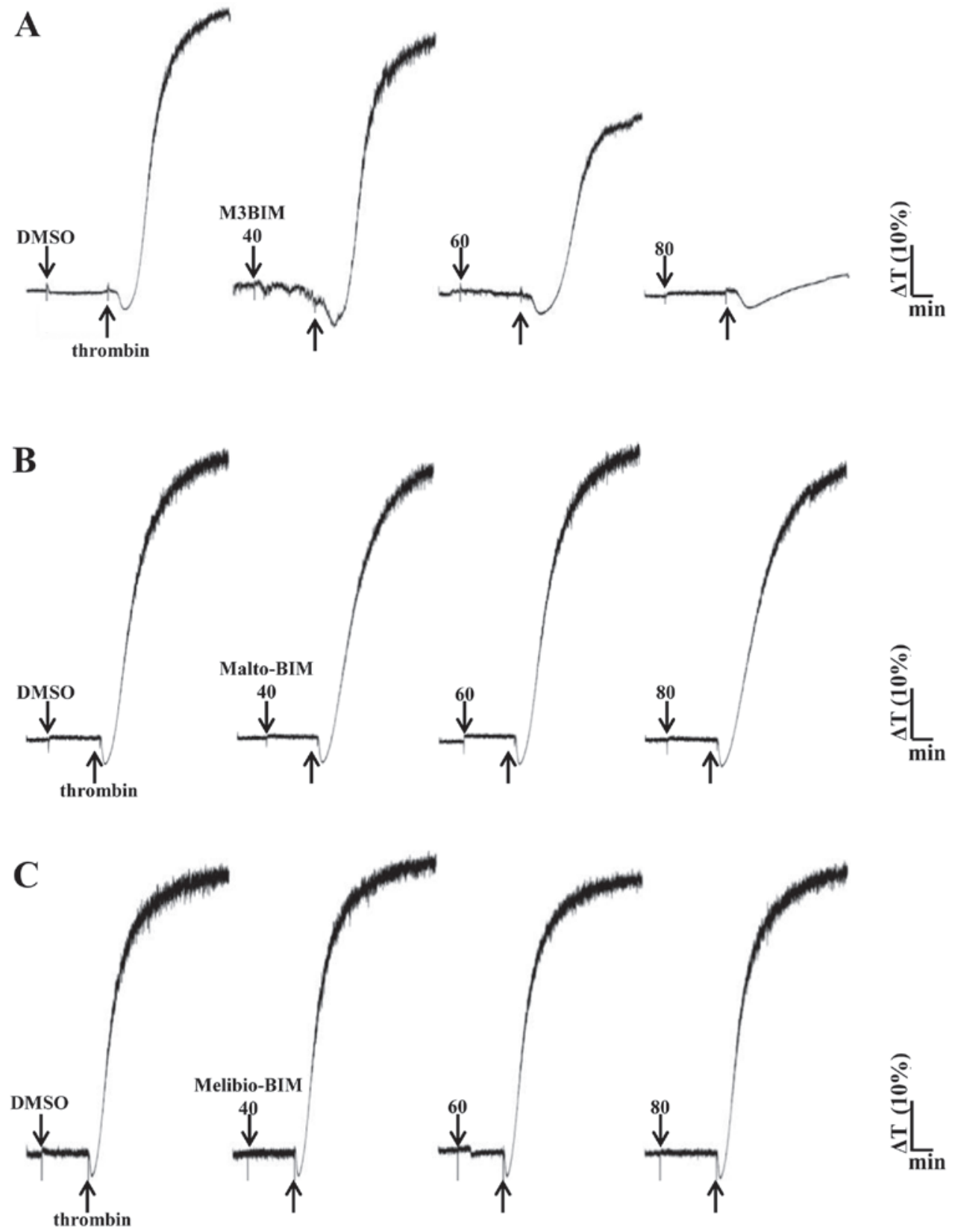

Figure 3. Effects of the test compounds on the inhibition of platelet aggregation in washed human platelets stimulated with thrombin. Washed platelets (3.6x $10^{8}$ cells $/ \mathrm{ml}$ ) were pre-treated with 40-80 $\mu \mathrm{M}$ of each (A) M3BIM, (B) Malto-BIM and (C) Melibio-BIM, and then 0.01 U/ml thrombin was added to induce platelet aggregation. The profiles are representative examples of 4 similar experiments.

the test compounds M3BIM, Malto-BIM and Melibio-BIM affect collagen-induced-platelet granule secretion. Consistent with the aggregation experiment, only the compound M3BIM $(60 \mu \mathrm{M})$ significantly inhibited collagen-induced ATP release in washed human platelets (Fig. 4A). This suggests that M3BIM attenuates platelet dense-granule secretion.

It is well known that intracellular calcium ion $\left[\mathrm{Ca}^{2+}\right]_{\mathrm{i}}$ plays a critical role in agonist-induced platelet aggregation (14). That is, $\left[\mathrm{Ca}^{2+}\right]_{\mathrm{i}}$ activates downstream signaling molecules, and thus, it is the prerequisite for the full activation of platelets. Therefore, we analyzed the inhibitory effects of the test compounds on $\mathrm{Ca}^{2+}$ mobilization in human platelets. When the platelets were stimulated with collagen, the level of $\left[\mathrm{Ca}^{2+}\right]_{i}$ was significantly increased. However, this was markedly diminished only by pre-treatment with M3BIM, but not by Malto-BIM and Melibio-BIM (Fig. 4B). This result suggested that the antiplatelet activity of M3BIM may be mediated by the inhibition of cytoplasmic calcium increase.

M3BIM suppresses the phosphorylation of $p 47$ and $p 38$ MAPK. To investigate the effects of newly synthesiszed imidazole compounds on the downstream pathway of collagen-induced PKC activation, the phosphorylation of p47 was measured in collagen-stimulated platelets. The stimulation of platelets with a number of different agonists induces the activation of PKC, which then phosphorylates p47 protein (pleckstrin) (15). When collagen $(1 \mu \mathrm{g} / \mathrm{ml})$ was added to human platelets, p47 protein was predominately phosphorylated compared 

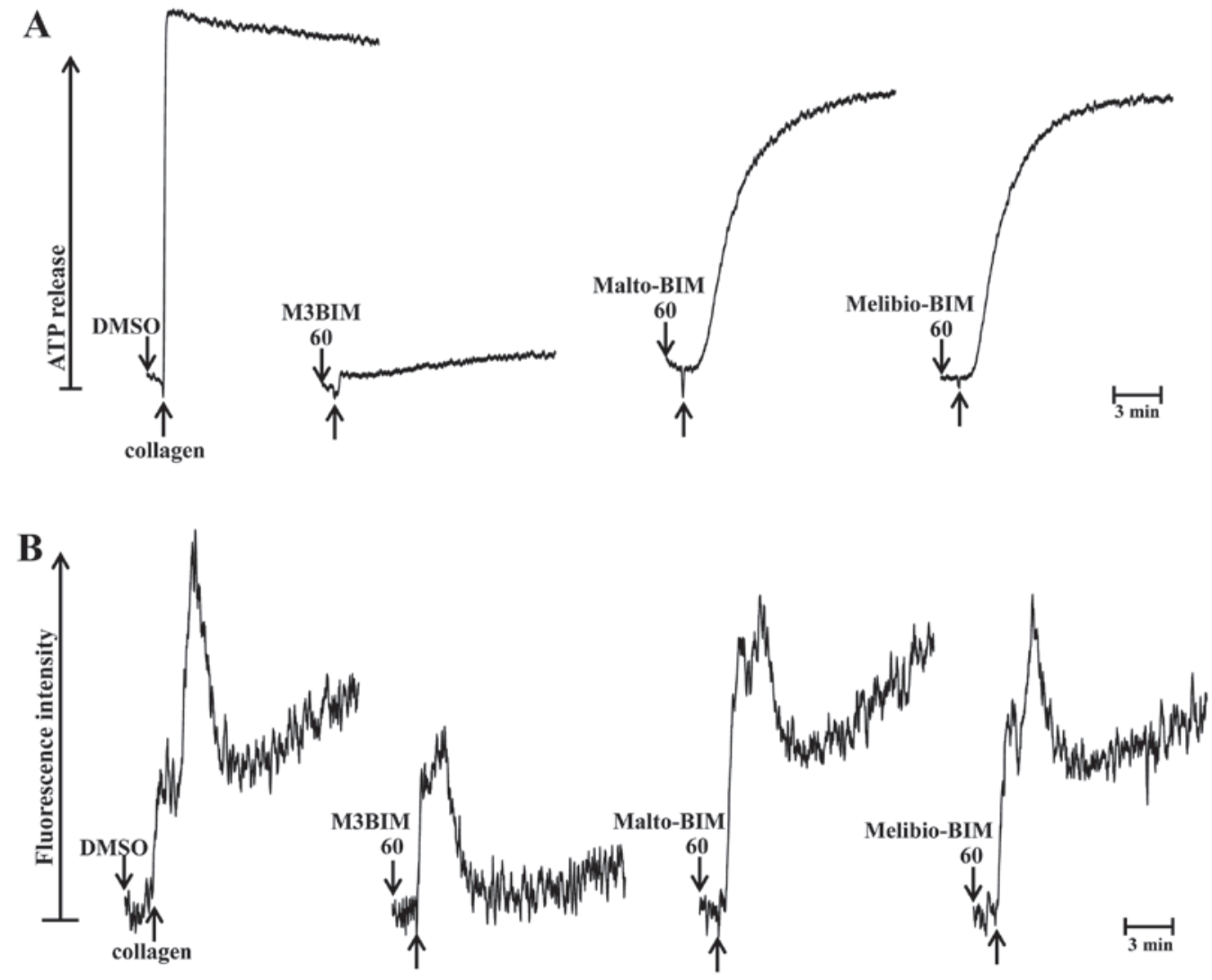

C

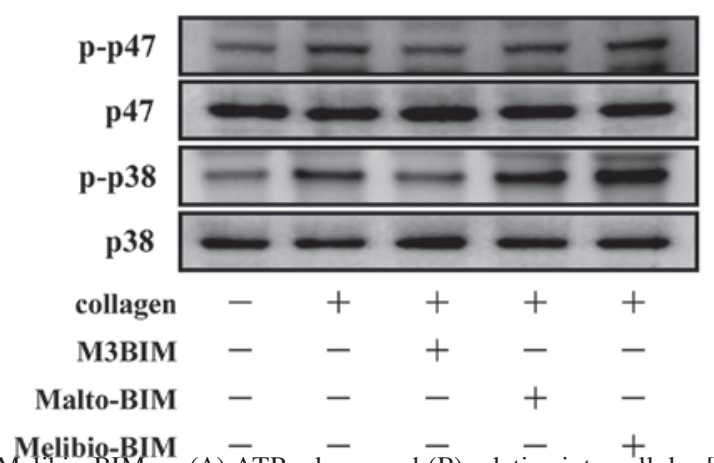

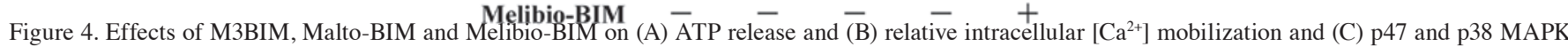
phosphorylation in collagen-activated platelets. Washed platelets were pre-treated with $60 \mu \mathrm{M}$ of each M3BIM, Malto-BIM and Melibio-BIM, and then $1 \mu \mathrm{g} / \mathrm{ml}$ collagen was added to induce platelet activation. The profiles are representative examples of 4 similar experiments.

with resting platelets. Of the three compounds tested, only compound M3BIM $(60 \mu \mathrm{M})$ inhibited collagen-induced p47 phosphorylation (Fig. 4C), whereas Malto-BIM (60 $\mu \mathrm{M})$ and Melibio-BIM $(60 \mu \mathrm{M})$ did not affect this phosphorylation with the same concentration.

It has been well established that MAPKs, p38 MAPK, JNK and ERK, are present in platelets and that they are activated by various agonists (16). The activation of MAPKs plays an important role in the secretion of platelet granules. In this study, we determined whether collagen-induced platelet p38 MAPK phosphorylation may be modulated as a signaling pathway by the test compounds. Consistent with the inhibitory effect of M3BIM on collagen-induced p47 phosphorylation, this compound significantly abolished p38 MAPK phosphorylation as shown in Fig. 4C. The other compounds Malto-BIM and Melibio-BIM did not seem to be effective; the fact that they were not effective may be attributed to the fact that these compounds have a lower number (two) of sugar moieties in the imidazole ring than M3BIM (three). These results suggest that the antiplatelet effect of M3BIM may be mediated via the inhibition of the activation of hte PKC/p38 MAPK signaling pathway.

Toxicity of M3BIM, Malto-BIM and Melibio-BIM. We assessed the toxic effects of M3BIM, Malto-BIM and Melibio-BIM in wild-type zebrafish embryos treated for 3 days post-fertilization with a range of doses of $(25-200 \mu \mathrm{M})$. The results revealed no significant phenotypic differences between the solvent control (0.5\% DMSO)- and test compound-treated zebrafish embryos throughout the experiment $(n=15)$ (Fig. 5). It is noteworthy that no developmental defects or decreases in viability were observed in the presence of M3BIM, Malto-BIM and Melibio-BIM, even at the highest concentration of $200 \mu \mathrm{M}$. This indicates that M3BIM exhibits antiplatelet activity without causing genotoxicity. 
A

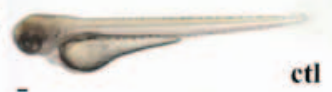

$-$

etl
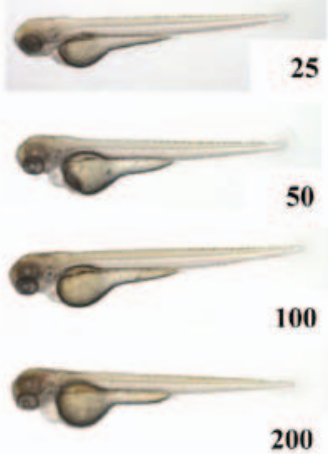

B

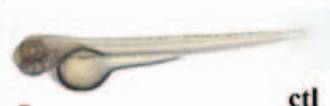

$-$

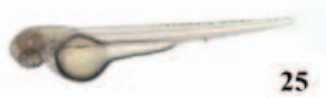

50
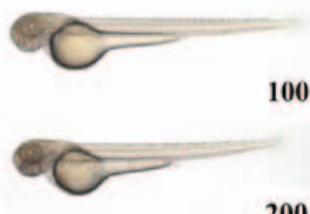

200

C

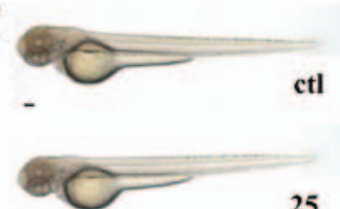

25

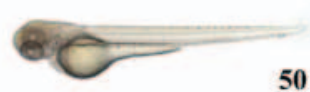

50

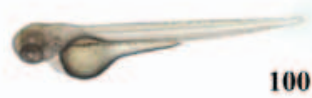

200
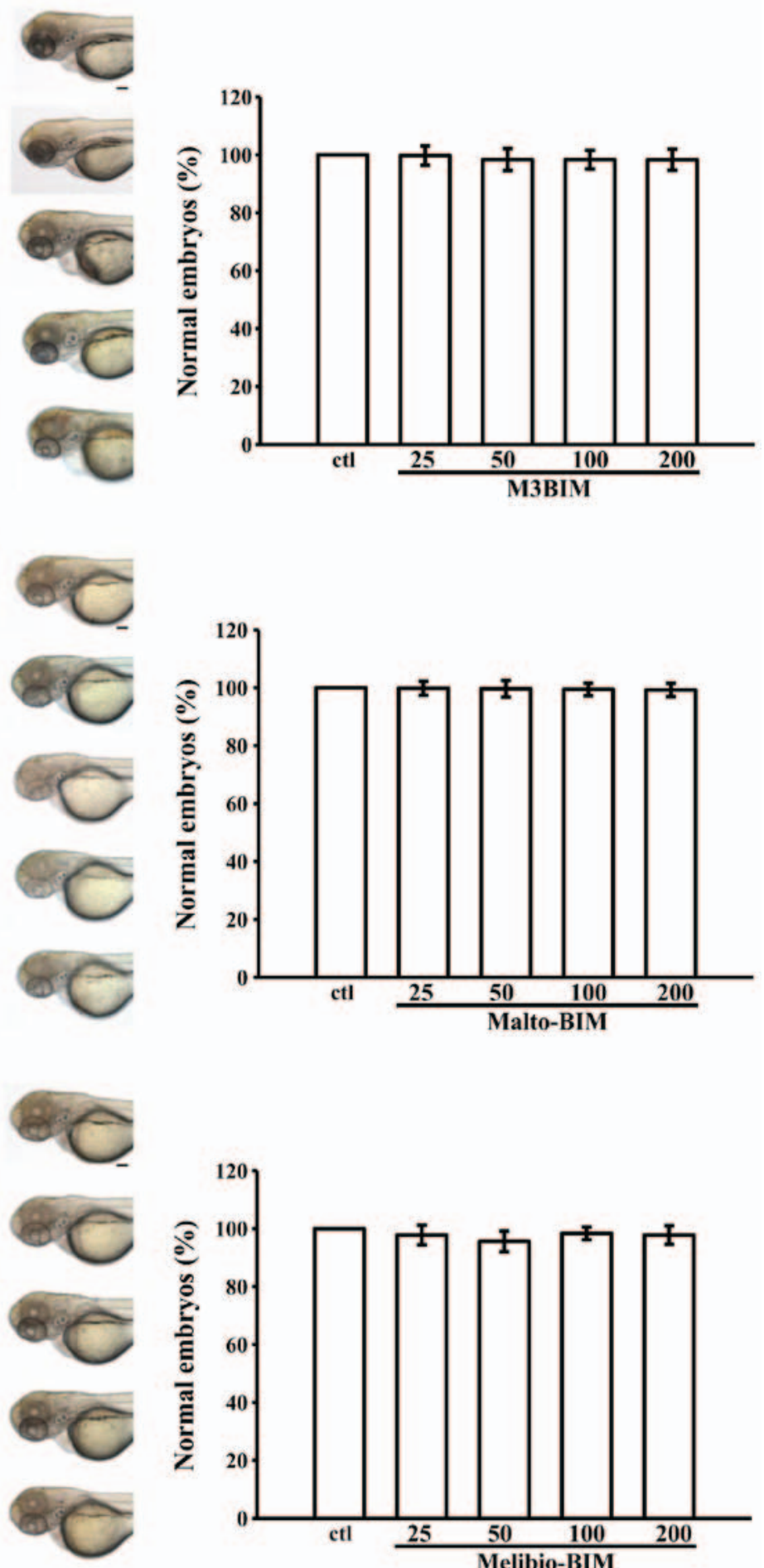

Figure 5. Determination of toxic effects of (A) M3BIM,(B) Malto-BIM or (C) Melibio-BIM on a zebrafish embryonic developmental model. Wild-type zebrafish embryos at 3 days post-fertilization exposed to various concentrations of M3BIM, Malto-BIM or Melibio-BIM (25, 50, 100 and 200 $\mu \mathrm{M})$ or a solvent control (0.5\% DMSO); Scale bar, $100 \mu \mathrm{m}$, [(A-C) left panel]. Statistical graphs [(A-C) right panel] show the means $\pm \mathrm{SEM}(\mathrm{n}=15)$.

\section{Discussion}

Benzimidazole derivatives belong to selected molecules that can be used to synthesize new substances with various biological properties (17). The most noteworthy finding from the present study was the direct antiplatelet potential of newly derived imidazole-labeled saccharide compounds M3BIM, Malto-BIM and Melibio-BIM in vitro. As collagen and thrombin are considered to be potent agonists for platelet and a component of subendothelial matrix in blood vessel, they were used to induce platelet aggregation. Of the three compounds tested, only compound M3BIM significantly and concentration-dependently impaired collagen and thrombininduced platelet aggregation. Moreover, Malto-BIM and Melibio-BIM did not affect the responses stimulated either by collagen or thrombin in human platelets. To elucidate the molecular aspects of the antiplatelet effects of M3BIM, we further analyzed downstream signaling using the intracellular 
$\mathrm{Ca}^{2+}$ concentration, dense granule secretions and protein phosphorylations (e.g., p38 MAPK and p47).

Numerous studies have defined the role of dense granules in platelets. A platelet contains approximately 2-7 dense granules. The activation of platelets leads to the secretion of dense granule components, such as ATP, ADP, calcium and serotonin (18). These materials play a crucial role in constricting damaged blood vessels and aggregating platelets. Calcium is an important second messenger in the platelet activation cascade. A previous study evidenced that collagen activation in human platelets requires an increase in the levels of $\left[\mathrm{Ca}^{2+}\right]$ i (19). Another study confirmed that in response to a moderate dose of collagen $(10 \mu \mathrm{g} / \mathrm{ml})$, approximately $70 \%$ of the increase in $\left[\mathrm{Ca}^{2+}\right]_{\mathrm{i}}$ levels was due to the influx of $\mathrm{Ca}^{2+}$ from the extracellular milieu, with the remainder as a function of $\mathrm{Ca}^{2+}$ release from the dense tubular system (20). Our previous studies demonstrated that the inhibition of relative intracellular $\left[\mathrm{Ca}^{2+}\right]$ mobilization and ATP-release reaction contributed to the antiaggregant effects of natural substances against agonist induced platelets aggregation (21-23). Rakesh et al (24) demonstrated that synthesized ibuprofen derivatives exert antiplatelet effects by inhibiting $\mathrm{Ca}^{2+}$. In this study, we found that M3BIM significantly blocked collagen-activated calcium-ion mobilization and ATP secretion to a lesser extent in human platelets (Fig. 4). This indicated that M3BIM impaired dense granule secretion, which is an earlier phase of platelet activation process.

It is well established that MAPKs, including ERKs, JNKs, and p38 MAPK, are found in platelets (25) where they are activated by collagen and thrombin, and are involved in thrombosis. ERK and p38 MAPK play important roles in stimulating the secretion of granules and facilitating clot retraction. During platelet activation, the arachidonic acid (AA) metabolism may deal a positive feedback amplifier to activate p38 MAPK, followed by the stimulation of cytosolic phospholipase $\mathrm{A}_{2}$, which promotes thromboxane $\mathrm{A}_{2}\left(\mathrm{Tx}_{2}\right)$ formation (26). In this study, we demonstrated that the collagen-induced activation of p38 MAPK was inhibited by M3BIM, but not by Malto-BIM and Melibio-BIM, suggesting that M3BIM attenuated platelet activation, at least in part, through the p38 MAPK signaling pathway. PKC is rapidly activated in agonist-stimulated platelets. It comprises a large family of closely-related serine/ threonine protein kinases, classed according to their co-factor requirements. Conventional $(\alpha, \beta \mathrm{I}, \beta \mathrm{II}$ and $\gamma)$ family members are dependent on calcium, phospholipid and diacylglycerol for activation, whereas non-conventional isoforms $[\delta, \varepsilon, \eta(\mathrm{L}), \theta$ and $\mu$ ] are insensitive to calcium. An often used measure of PKC activation in agonist stimulated cells is the phosphorylation of defined substrate proteins. In platelets and other cells of hematopoietic origin, the major PKC substrate is the p47 phosphoprotein, pleckstrin (platelet and leukocyte $\mathrm{C}$ kinase substrate), which is rapidly phosphorylated in response to a variety of agonists, including thrombin, thrombin receptor activating peptide (TRAP), as well as phorbol ester (27). Previous studies have demonstrated that natural compounds such as CME-1, a polysaccharide $(23,28)$, sulforaphane, a naturally occurring isothiocyanate (22), hinokitiol, a tropolone derivatives (29), and andrographolide, a labdane diterpene lactone (21), exert their antiplatelet effects against various agonist-induced human platelets via the suppression of p38 MAPK or p47 phosphoproteins. These results support the findings of the present study in that the imidazole-derived saccharide compound, M3BIM, inhibited collagen-induced platelet activation and that this effect may be at least partly mediated via the suppression of p38 MAPK and p47 protein phosphorylation.

Moreover, in the present study, the toxicity of imidazolederived saccharide compounds was tested using a zebrafish toxicity method, as previously described (30). It is notable that no developmental defects or decreases in viability were observed in the presence of the test compounds, indicating that compared to the other two compounds, M3BIM exerted its antiplatelet activity without causing any genotoxicity. Recent studies have also used zebrafish assay to examine the toxic effects of synthetic compounds, such as thiazole compounds (31), quinoline-derived trifluoromethyl alcohols (32) and brominated compounds (33) for the evaluation of their respective biological effects.

A stable Tx $\mathrm{A}_{2}$ metabolite, thromboxane $\mathrm{B}_{2}\left(\mathrm{TxB}_{2}\right)$, is widely used as a prognostic risk marker of platelet activation in cardiovascular disease, which is closely related to cyclooxygenase (COX-1) and thromboxane synthetase (TXS) activity (34). A recent study found that a series of thioureas derivatives reduced $\mathrm{TxB}_{2}$ production in human platelets via the direct inhibition of COX-1 for their antiplatelet effects (35). Currently, the basic structural requirements for the selective inhibition of TXS are a 1-imidazolyl or a 3-pyridyl moiety at one end of the molecule (36). In addition, the increases of chain length of bioactive molecules for improved lipophilicity have been reported as a relevant parameter to inhibit human platelet aggregation (37). Some conceivable reasons may be drawn from the abovementioned evidence regarding the association between chemical structure and antiplatelet activity of the tested compounds. It is clear that among the three compounds tested, only compound M3BIM exerted a greater inhibitory effect against collageninduced platelet aggregation. A plausible explanation of this effect that M3BIM possesses 1-imidazolyl moiety at one end and has longer chain length (three sugar moieties attached at one end in imidazole ring; whereas Malto-BIM and Melibio-BIM hold only two sugar moieties). This suggests that the number of sugar moiety in imidazole ring of the test compounds is important for their antiplatelet activity. Considering the only structural differences among the test compounds, M3BIM has a longer chain length with an increased number of free $\mathrm{OH}$ groups. Consistent with this structure, a previous study stated that compounds with more free $\mathrm{OH}$ groups are critical for its antiplatelet function (38). However, additional mechanistic studies are warranted in order to validate whether M3BIM directly inhibits $\mathrm{TxA}_{2}$ via suppressing COX-1 and TXS or its $\mathrm{OH}$ group play role to exert its antiplatelet effect.

In conclusion, our study indicates that among the three newly synthesized imidazole-based saccharide compounds, only compound M3BIM exerted a potent inhibitory effect against induced in vitro platelet aggregation. A noteworthy finding of this study was that the antiplatelet activity of M3BIM may originally obstruct the phosphorylation of p38 MAPK and $\mathrm{p} 47$, then inhibit intracellular $\left[\mathrm{Ca}^{2+}\right]$ mobilization and ATP release reaction, and eventually, inhibit platelet activation. As compounds with anti-platelet property stand better and receive much attention by the medical practitioners in order to treat thrombolytic disorders, the results of the present study may contribute to a better understanding of benzimidazole derivatives for their platelet protective properties. 


\section{Acknowledgements}

The present study was supported by grants (nos. MOST1032320-B-038-017, MOST104-2622-B-038-003, and MOST 104-2320-B-038-045-MY2) from the Ministry of Science and Technology of Taiwan, the Wan-Fang Hospital-Taipei Medical University (no. 102TMU-WFH-02-1), and Shin Kong Wu Memorial Hospital (no. SKH-8302-103-DR-28).

\section{References}

1. Murray CJ and Lopez AD: Mortality by cause for eight regions of the world: Global Burden of Disease Study. Lancet 349: 1269-1276, 1997

2. Tantry US, Bliden KP and Gurbel PA: Resistance to antiplatelet drugs: Current status and future research. Expert Opin Pharmacother 6: 2027-2045, 2005.

3. Cox D: Oral GPIIb/IIIa antagonists: What went wrong? Curr Pharm Des 10: 1587-1596, 2004

4. Herbert JM, Hérault JP, Bernat A, Savi P, Schaeffer P, Driguez PA Duchaussoy P and Petitou M: SR123781A, a synthetic heparin mimetic. Thromb Haemost 85: 852-860, 2001.

5. Petitou M, Hérault JP, Bernat A, Driguez PA, Duchaussoy P, Lormeau JC and Herbert JM: Synthesis of thrombin-inhibiting heparin mimetics without side effects. Nature 398: 417-422, 1999

6. Dogné JM, Hanson J, de Leval X, Masereel B, Kolh P and Pirotte B: New developments on thromboxane modulators. Mini Rev Med Chem 4: 649-657, 2004.

7. Zhao Z, Arnaiz DO, Griedel B, Sakata S, Dallas JL, Whitlow M, Trinh L, Post J, Liang A, Morrissey MM and Shaw KJ: Design, synthesis, and in vitro biological activity of benzimidazole based factor Xa inhibitors. Bioorg Med Chem Lett 10: 963-966, 2000.

8. Kucheryavenko AF, Spasov AA, Petrov VI and Anisimova VA Antiaggregant activity of a new benzimidazole derivative. Bull Exp Biol Med 156: 796-798, 2014.

9. GreinacherA,AlbanS,DummelV,FranzGandMueller-EckhardtC: Characterization of the structural requirements for a carbohydrate based anticoagulant with a reduced risk of inducing the immunological type of heparin-associated thrombocytopenia. Thromb Haemost 74: 886-892, 1995.

10. Lin C, Lai PT, Liao SK, Hung WT, Yang WB and Fang JM: Using molecular iodine in direct oxidative condensation of aldoses with diamines: An improved synthesis of aldo-benzimidazoles and aldo-naphthimidazoles for carbohydrate analysis. J Org Chem 73: 3848-3853, 2008.

11. Sheu JR, Lee CR, Lin CH, Hsiao G, Ko WC, Chen YC and Yen MH: Mechanisms involved in the antiplatelet activity of Staphylococcus aureus lipoteichoic acid in human platelets. Thromb Haemost 83: 777-784, 2000.

12. Westerfield M: The Zebrafish Book: A Guide for the Laboratory Use of Zebrafish (Brachydanio rerio). University of Oregon Press, Eugene, OR, 1993.

13. Mackman N: Triggers, targets and treatments for thrombosis. Nature 451: 914-918, 2008.

14. Kang WS, Chung KH, Chung JH, Lee JY, Park JB, Zhang YH, Yoo HS and Yun YP: Antiplatelet activity of green tea catechins is mediated by inhibition of cytoplasmic calcium increase. J Cardiovasc Pharmacol 38: 875-884, 2001.

15. Tyers M, Rachubinski RA, Stewart MI, Varrichio AM, Shorr RG, Haslam RJ and Harley CB: Molecular cloning and expression of the major protein kinase $\mathrm{C}$ substrate of platelets. Nature 333: $470-473,1988$

16. Toth-Zsamboki E, Oury C, Cornelissen H, De Vos R, Vermylen J and Hoylaerts MF: P2X1-mediated ERK2 activation amplifies the collagen-induced platelet secretion by enhancing myosin light chain kinase activation. J Biol Chem 278: 46661-46667, 2003.

17. Nofal ZM, Soliman EA, Abd El-Karim SS, El Zahar MI, Srour AM, Sethumadhavan S and Maher TJ: Novel benzimidazole derivatives as expected anticancer agents. Acta Pol Pharm 68: 519-534, 2011.

18. Unsworth AJ, Smith H, Gissen P, Watson SP and Pears CJ: Submaximal inhibition of protein kinase $\mathrm{C}$ restores ADP-induced dense granule secretion in platelets in the presence of $\mathrm{Ca}^{2+}$. $\mathrm{J}$ Biol Chem 286: 21073-21082, 2011

19. Roberts DE, McNicol A and Bose R: Mechanism of collagen activation in human platelets. J Biol Chem 279: 19421-19430, 2004.
20. Roberts DE and Bose R: Reverse mode $\mathrm{Na}+/ \mathrm{Ca}^{2+}$ exchange in the collagen activation of human platelets. Ann NY Acad Sci 976: 345-349, 2002

21. Lu WJ, Lee JJ, Chou DS, Jayakumar T, Fong TH, Hsiao G and Sheu JR: A novel role of andrographolide, an NF-kappa B inhibitor, on inhibition of platelet activation: The pivotal mechanisms of endothelial nitric oxide synthase/cyclic GMP. J Mol Med (Berl) 89: 1261-1273, 2011.

22. Jayakumar T, Chen WF, Lu WJ, Chou DS, Hsiao G, Hsu CY, Sheu JR and Hsieh CY: A novel antithrombotic effect of sulforaphane via activation of platelet adenylate cyclase: Ex vivo and in vivo studies. J Nutr Biochem 24: 1086-1095, 2013.

23. Chang Y,Hsu WH, Lu WJ, JayakumarT, Liao JC, Lin MJ, Wang SH, Geraldine P, Lin KH and Sheu JR: Inhibitory mechanisms of CME-1, a novel polysaccharide from the mycelia of Cordyceps sinensis, in platelet activation. Curr Pharm Biotechnol 16: 451-461, 2015.

24. Rakesh KS, Jagadish S, Vinayaka AC, Hemshekhar M, Paul M, Thushara RM, Sundaram MS, Swaroop TR, Mohan CD, Basappa, et al: A new ibuprofen derivative inhibits platelet aggregation and ROS mediated platelet apoptosis. PLoS One 9: e107182, 2014.

25. Bugaud F, Nadal-Wollbold F, Lévy-Toledano S, Rosa JP and Bryckaert M: Regulation of c-jun-NH2 terminal kinase and extracellular-signal regulated kinase in human platelets. Blood 94: 3800-3805, 1999.

26. Coulon L, Calzada C, Moulin P, Véricel E and Lagarde M: Activation of p38 mitogen-activated protein kinase/cytosolic phospholipase A2 cascade in hydroperoxide-stressed platelets. Free Radic Biol Med 35: 616-625, 2003.

27. Tyers M, Haslam RJ, Rachubinski RA and Harley CB: Molecular analysis of pleckstrin: The major protein kinase $\mathrm{C}$ substrate of platelets. J Cell Biochem 40: 133-145, 1989.

28. Lu WJ, Chang NC, Jayakumar T, Liao JC, Lin MJ, Wang SH, Chou DS, Thomas PA and Sheu JR: Ex vivo and in vivo studies of CME-1, a novel polysaccharide purified from the mycelia of Cordyceps sinensis that inhibits human platelet activation by activating adenylate cyclase/cyclic AMP. Thromb Res 134: 1301-1310, 2014.

29. Lin KH, Kuo JR, Lu WJ, Chung CL, Chou DS, Huang SY, Lee HC and Sheu JR: Hinokitiol inhibits platelet activation ex vivo and thrombus formation in vivo. Biochem Pharmacol 85: 1478-1485, 2013.

30. He N, Li X, Feng D, Wu M, Chen R, Chen T, Chen D and Feng X: Exploring the toxicity of a bismuth-asparagine coordination polymer on the early development of zebrafish embryos. Chem Res Toxicol 26: 89-95, 2013.

31. Chen MC, Zhou B, Zhang K, Yuan YC, Un F, Hu S, Chou $\mathrm{CM}$, Chen $\mathrm{CH}$, Wu J, Wang Y, et al: The novel ribonucleotide reductase inhibitor $\mathrm{COH} 29$ inhibits DNA repair in vitro. Mol Pharmacol 87: 996-1005, 2015.

32. Sittaramane V, Padgett J, Salter P, Williams A, Luke S, McCall R, Arambula JF, Graves VB, Blocker M, Van Leuven D, et al: Discovery of quinoline-derived trifluoromethyl alcohols, determination of their in vivo toxicity and anticancer activity in a zebrafish embryo model. ChemMedChem 10: 1802-1807, 2015.

33. Yang J and Chan KM: Evaluation of the toxic effects of brominated compounds (BDE-47, 99, 209, TBBPA) and bisphenol A (BPA) using a zebrafish liver cell line, ZFL. Aquat Toxicol 159: 138-147, 2015.

34. Sathler PC, Santana M, Lourenço AL, Rodrigues CR, Abreu P, Cabral LM and Castro HC: Human thromboxane synthase: Comparative modeling and docking evaluation with the competitive inhibitors Dazoxiben and Ozagrel. J Enzyme Inhib Med Chem 29: 527-531, 2014.

35. Lourenço AL, Saito MS, Dorneles LE, Viana GM, Sathler PC, Aguiar LC, de Pádula M, Domingos TF, Fraga AG, Rodrigues CR, et al: Synthesis and antiplatelet activity of antithrombotic thiourea compounds: Biological and structure-activity relationship studies. Molecules 20: 7174-7200, 2015.

36. Liedtke AJ, Crews BC, Daniel CM, Blobaum AL, Kingsley PJ, Ghebreselasie K and Marnett LJ: Cyclooxygenase-1-selective inhibitors based on the (E)-2'-des-methyl-sulindac sulfide scaffold. J Med Chem 55: 2287-2300, 2012.

37. Reyes JJ, De La Cruz JP, Muñoz-Marin J, Guerrero A, Lopez-Villodres JA, Madrona A, Espartero JL and GonzalezCorrea JA: Antiplatelet effect of new lipophilic hydroxytyrosol alkyl ether derivatives in human blood. Eur J Nutr 52: 591-599, 2013.

38. Guo C, Liu S, Guo Y, Yin Y, Lin J, Chen X and Sun MZ: Comparative function-structural analysis of antiplatelet and antiradical activities of flavonoid phytochemicals. J Anim Plant Sci 24: 926-935, 2014. 